\title{
A novel curcuminoid exhibits enhanced antitumor activity in nasopharyngeal carcinoma
}

\author{
YUNBAO PAN ${ }^{1-3^{*}}$, GUOHONG LIU ${ }^{4 *}$, JIAN XIAO $^{3,5^{*}}$, BOJIN SU $^{3}$, FULING ZHOU $^{6}$ and YONGCHANG WEI $^{7}$ \\ ${ }^{1}$ Department of Pathology, Affiliated Hospital, Jiangnan University, Wuxi, Jiangsu 214062; ${ }^{2}$ Department of Pathology, \\ Wuxi Medical School, Jiangnan University, Wuxi, Jiangsu 214122; ${ }^{3}$ Department of Pathophysiology, \\ Zhongshan School of Medicine, Sun Yat-Sen University, Guangzhou 510080; ${ }^{4}$ School of Materials Science and Engineering, \\ Sun Yat-Sen University, Guangzhou 510275; ${ }^{5}$ Zhejiang Key Laboratory of Biotechnology Pharmaceutical Engineering, \\ School of Pharmacy, Wenzhou Medical University, Wenzhou 325025; Departments of ${ }^{6}$ Hematology and \\ ${ }^{7}$ Radiation and Medical Oncology, Zhongnan Hospital of Wuhan University, Wuhan, Hubei 430071, P.R. China
}

Received December 23, 2015; Accepted February 18, 2016

DOI: 10.3892/ijo.2016.3425

\begin{abstract}
Curcumin shows growth-inhibition against tumor cells through multi-target mechanisms. Nevertheless, the poor stability and pharmacokinetics considerably limit its clinical functions. Increased effort has been put into the chemical alteration of curcumin to find potential analogues with improved bioavailability and antitumor activities. In this study, the antitumor activity of a novel curcuminoid (B63) in nasopharyngeal carcinoma (NPC) was examined. The MTT and colony formation assays were used to detect NPC cell viability and proliferation. Flow cytometry was used to detect cell cycle distribution. The Annexin V/PI staining assay and cleavage PARP and cleavage caspase-3 expression were used to examine apoptosis. Western blotting was used to examine the protein expression of endoplasmic reticulum (ER) stress pathway markers, XBP-1, ATF-4 and CHOP. The suppressive effect of $\mathrm{B} 63$ on tumor growth was examined in vivo by subcutaneously inoculated NPC in a tumor model using nude mice. Treatment with B63 potentially caused growth inhibition and apoptosis in NPC cells in a dose- and time-responsive manner. Its antitumor effect was associated with the ER stress activation. Nevertheless, the same dose of curcumin did not
\end{abstract}

Correspondence to: Professor Fuling Zhou, Department of Hematology, Zhongnan Hospital of Wuhan University, 169 Donghu Road, Wuhan 430071, P.R. China

E-mail: zhoufuling@163.com

Professor Yongchang Wei, Department of Radiation and Medical Oncology, Zhongnan Hospital of Wuhan University, 169 Donghu Road, Wuhan 430071, P.R. China

E-mail: weiyongchang8@163.com

*Contributed equally

Key words: nasopharyngeal carcinoma, curcumin, cell cycle, endoplasmic reticulum stress activate ER stress. In addition, knockdown of CHOP attenuated B63-induced cell viability inhibition, suggesting that the apoptotic pathway is ER stress-dependent. The tumor volume and weight were significantly reduced by pretreating the NPC cells with B63 before implantation in the in vivo mouse model. B63 exhibited a more potent antitumor action than curcumin in NPC. These observations on the novel compound B63 indicate a novel candidate for NPC therapy.

\section{Introduction}

Nasopharyngeal carcinoma (NPC) is the most prevalent malignant cancer in Southeast Asia particularly in South China (1). Radiotherapy and cisplatin based chemotherapy are the main therapy for NPC $(2,3)$. Unfortunately, most patients suffering from NPC do not benefit much from simultaneous chemoradiotherapy; as 30-40\% develop distant metastases within 4 years (4), and once metastasis occurs, the prognosis is very poor. Therefore, it is critical to look for new treatments for NPC.

An increasing amount of attention has been given to the utilization of complementary and alternative medicine as a part of the therapy for various cancers associated with current treatments (5). Curcumin has been reported to arrest the cell cycle, induce apoptosis and prevent the propagation and metastasis of tumor cells including NPC $(6,7)$. It has been reported that curcumin exerts its proapoptotic effects by producing endoplasmic reticulum (ER) stress in cancer cells $(8,9)$. Curcumin is notably non-toxic and possesses promising anticancer activities, however, preclinical and clinical studies showed its low bioavailability and pharmacokinetic profiles as a result of its instability under physiological conditions which have limited its utilization in anticancer treatments $(9,10)$.

Substantial work was done in modifying curcumin structure to determine analogues with stronger antitumor activities and better bioavailability $(11,12)$. A series of mono-carbonyl analogues of curcumin have been synthesized by removing the $\beta$-diketone moiety $(13,14)$. Studies have shown that some monocarbonyl analogues possess enhanced stability and antitumor 
activities in vitro as well as improved pharmacokinetic profiles in vivo. One such compound, 1,5-bis(2-methoxyphenyl)-penta1,4-dien-3-one (B63) (Fig. 1B) was developed as part of a series of novel curcuminoids (15). Previous studies have shown that B63 exhibited stronger antitumor activtity than curcumin in human lung cancer cells (15). In this study, the biological activity of B63 on NPC cells was characterized. The data obtained demonstrated that B63 prevent cell viability, arrest cell cycle and induce apoptosis. B63 demonstrated a specificity for activating ER stress greater than curcumin. B63 therapy also showed improved growth-suppressive effects in vivo. The data obtained gave an indication that B63 could be further optimized for development for NPC therapy.

\section{Materials and methods}

Materials. Cell culture reagents were purchased from Invitrogen. The antibodies: CHOP, XBP-1, ATF-4, Lamin B, and Jab1 were from Santa Cruz, PARP and P27 were from BD Biosciences Pharmingen, caspase-3 and Cyclin B1 were from Cell Signaling Technology. Apoptosis (Annexin V/PI) staining kit was purchased from BD Biosciences. Curcumin and 3-(4,5)-dimethylthiahiazol-(-zy1)-3,5-di-phenyltetrazolium bromide (MTT) were from Sigma-Aldrich. B63 was from the School of Pharmacy, Wenzhou Medical University and stored in DMSO at a concentration of $50 \mathrm{mM}$. The final concentration of DMSO in the experimental system was $\leq 0.1 \%$.

Cell culture. NPC cells CNE1, CNE2 cells (16) and radioresistant NPC cell line CNE2R were cultured in RPMI-1640 medium as previously described (17).

MTT assay. To detect cell viability, we used MTT assay as previously described (16). Briefly, the cells seeded in 96-well plates (4,000 cells per well) were treated with B63 or curcumin for 24 or $48 \mathrm{~h}$. MTT (final concentration, $0.5 \mathrm{mg} / \mathrm{ml}$ ) was added to each well and incubated for $3.5 \mathrm{~h}$. The medium was discarded and $150 \mu \mathrm{l}$ of DMSO was added to each well, and incubated for $10 \mathrm{~min}$. The absorbance was read at $570 \mathrm{~nm}$. Half-Maximal inhibitory concentrations $\left(\mathrm{IC}_{50}\right)$, were used as the drug concentration to acquire half maximal inhibition of cell viability.

Colony formation assay. The colony formation assay was performed as described previously (18). Generally, cells (300 cells per well) seeded in a 6-well plate were treated with indicated doses of B63 for $24 \mathrm{~h}$. The NPC cells were cultured for 10 days and then stained with Giemsa dye and colonies of $\geq 50$ cells were counted by a microscope.

Cell cycle analysis by flow cytometry. PI staining was performed as previously described (18). Briefly, after applying $5 \mu \mathrm{M}$ of B63 or curcumin treatment, NPC cells were collected and fixed at $4{ }^{\circ} \mathrm{C}$ in $75 \%$ ethanol. Cells were washed two times in PBS, stained with PI, and analyzed immediately after staining using a flow cytometer (BD Biosciences).

Apoptosis measurement. To examine viable cells, nuclear staining was performed. Cells were exposed to $5 \mu \mathrm{M}$ B63 or curcumin for $48 \mathrm{~h}$ and were washed two times and fixed with methanol. After $15 \mathrm{~min}$, cells were rewashed and stained with Hoechst 33342 for $15 \mathrm{~min}$ and then detected using a fluorescence microscope (Olympus, DX50).

For Annexin V and PI staining, cells were treated with $5 \mu \mathrm{M}$ B63 or curcumin for $48 \mathrm{~h}$, and then collected and resuspended in $100 \mu \mathrm{l}$ binding buffer containing Annexin V-FITC and PI according to the manufacturer's instructions. Flow cytometer was used for the quantification of Annexin V-FITC and PI binding.

Lentiviral infection for CHOP siRNA. The CHOP siRNA sequence was designed as: 5'-GCAGGCAGGAAATCGAG CGCCTGAC-3'. The recombinant lentiviruses were produced by transfection of 293 T cells with FuGENE 6 Transfection reagent as described previously (15). Briefly, the subconfluent cells in a $10-\mathrm{cm}$ culture dish were co-transfected with lentiviral vector $(10 \mu \mathrm{g})$, lentiviral packaging vectors pRSV-REV $(2 \mu \mathrm{g})$ and pMDLg/pRRE (5 $\mu \mathrm{g})$ and the vesicular stomatitis virus $\mathrm{G}$ glycoprotein (VSVG) expression vector pMD2G (3 $\mu \mathrm{g})$. The viruses were collected from the culture supernatants on days 2 and 3 post-transfection, concentrated by ultracentrifugation for $1.5 \mathrm{~h}$ at 25,000 rpm and suspended in PBS. After infecting the NPC cells for $48 \mathrm{~h}$, knockdown of CHOP were further confirmed by immunoblot analysis.

Western blot analysis. After curcumin or B63 treatment whole cell lysate and nuclear and cytosolic extracts were isolated as described previously (15). Antibodies against the following proteins were used: CHOP, ATF-4, XBP-1, Lamin B. Immunoreactive bands were visualized with a secondary antibody and Western Lightning Chemiluminescence Plus reagent.

Tumorigenicity assay in nude mouse. NPC xenograft model was used to examine B63's antitumor activity as previously described (15). Four-week-old athymic nude (nu/nu) mice were obtained from the Animal Center of Sun Yat-Sen University. CNE2 and CNE2R were treated with either curcumin $(10 \mu \mathrm{M}), \mathrm{B} 63$ (5 and $10 \mu \mathrm{M})$, or DMSO for $12 \mathrm{~h}$ and then injected subcutaneously into the right flank of each mouse $\left(3 \times 10^{6}\right.$ cells/mouse, 6 mice/group). Mice were checked every 2 days for xenograft development. After tumors became obvious $\left(\sim 0.1 \mathrm{~mm}^{3}\right)$, tumor volumes was calculated using the following formula: length $\mathrm{x}$ width ${ }^{2} / 2$ every 3 days. At the end of the experiments the mice were sacrificed, and the tumors extracted for weighing. All the animal work was approved by the Institutional Animal Care and Use Committee of Sun Yat-sen University.

Statistical analysis. Results are shown as means \pm standard deviation. Statistical analysis for the results was performed using Student's t-test for only two groups, or one-way analysis of variance for more than two groups. Differences between groups were considered statistically significant at $\mathrm{P}<0.05$.

\section{Results}

B63 shows stronger antitumor activity than curcumin in suppressing NPC cell viability. In this study, the antitumor 
A
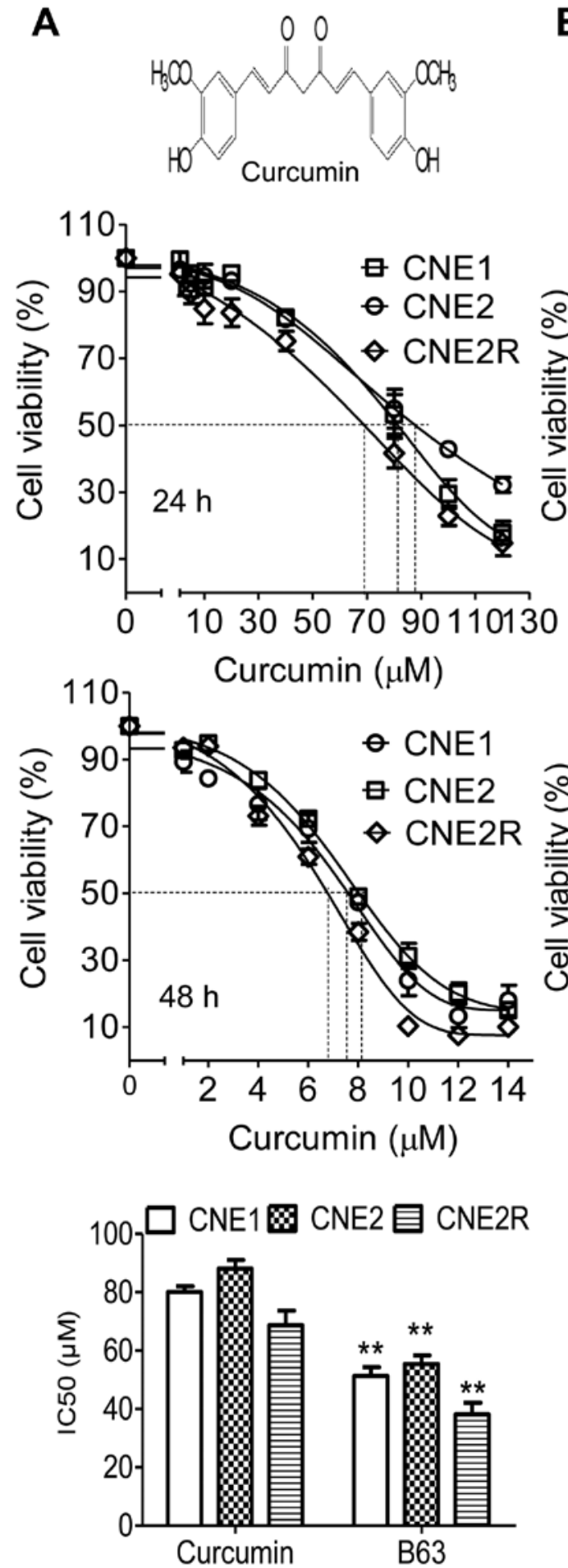

B<smiles>COc1ccccc1/C=C/C(=O)/C=C/c1ccccc1OC</smiles>

B63
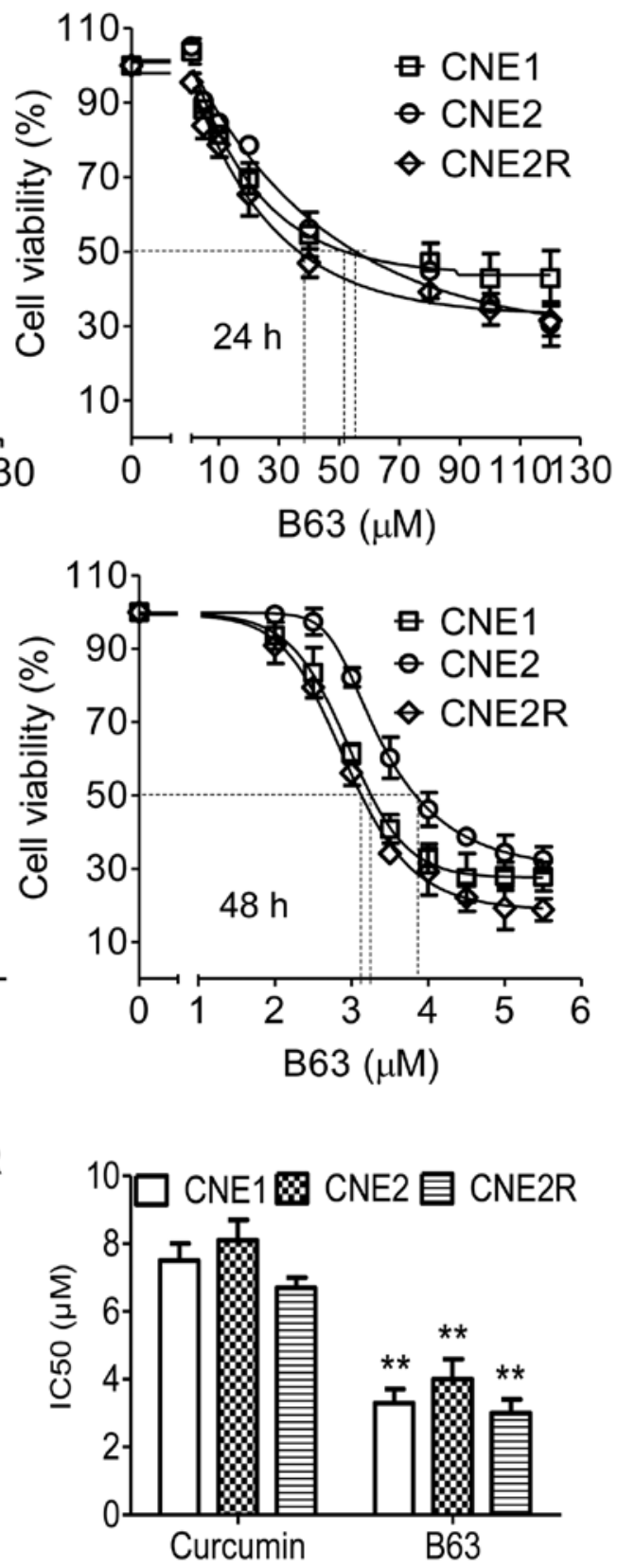

Figure 1. B63 inhibits NPC cell viability. The influence of curcumin (A) and B63 (B) on cell viability was determined by MTT assay. Cells were treated with indicated concentration of B63 or curcumin for 24 and $48 \mathrm{~h}$. The data represent three independent experiments, mean \pm SD. "*Compared with curcumin group, $\mathrm{P}<0.01$.

activities of B63 and curcumin in NPC cells were examined. After treatment for $24 \mathrm{~h}$, both B63 and curcumin showed suppression of cell viability in all three NPC cell types (Fig. 1). However, B63 exhibited greater inhibition than curcumin. $\mathrm{IC}_{50}$ values of $\mathrm{B} 63$ were 51, 55 and $38 \mu \mathrm{M}$ in CNE1, CNE2, and CNE2R, respectively, which are substantially more powerful than curcumin $\left(\mathrm{IC}_{50}\right.$ values 80,88 and $\left.69 \mu \mathrm{M}\right)$. In this study, B63 showed growth-suppressive activity in the NPC cell lines tested in a dose- and time-dependent manner, after 48-h treatment, the $\mathrm{IC}_{50}$ values of $\mathrm{B} 63$ were much lower, with 3.3, 4.0 and $3.0 \mu \mathrm{M}$ in CNE1, CNE2, and in CNE2R, respectively, which are also more powerful than curcumin $\left(\mathrm{IC}_{50}\right.$ values 7.5, 8.1 and $6.7 \mu \mathrm{M})$.

B63 is more powerful in inhibiting proliferation and inducing NPC cell cycle arrest. A colony formation assay to 

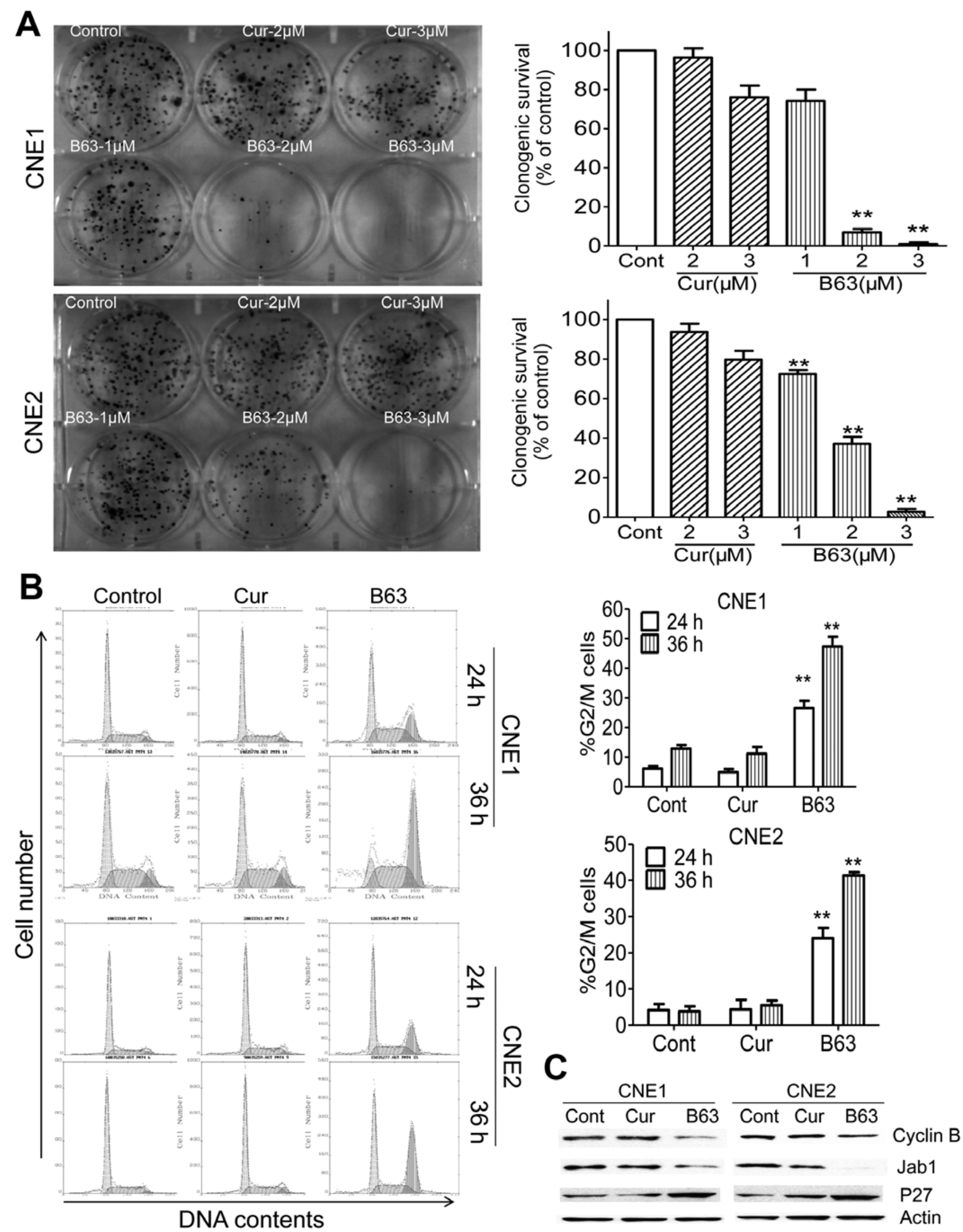

Figure 2. B63 inhibits cell proliferation in NPC. (A) Colony formation assay was performed to detect the effects of B63 on cell proliferation. Left, colonies were stained with Giemsa dye. Right, quantification of colonies. (B) The effects of B63 and curcumin on cell cycle were detected by flow cytometry analysis. Right, quantification of NPC cells in G2/M phase. (C) After 36-h treatment, the effect of B63 on Cyclin B and Jab1/P27 pathway was detemined by western blotting. Cont, control; Cur, curcumin. The data represent three independent experiments, mean $\pm \mathrm{SD}$. ${ }^{* *}$ Compared with curcumin group, $\mathrm{P}<0.01$. 
A
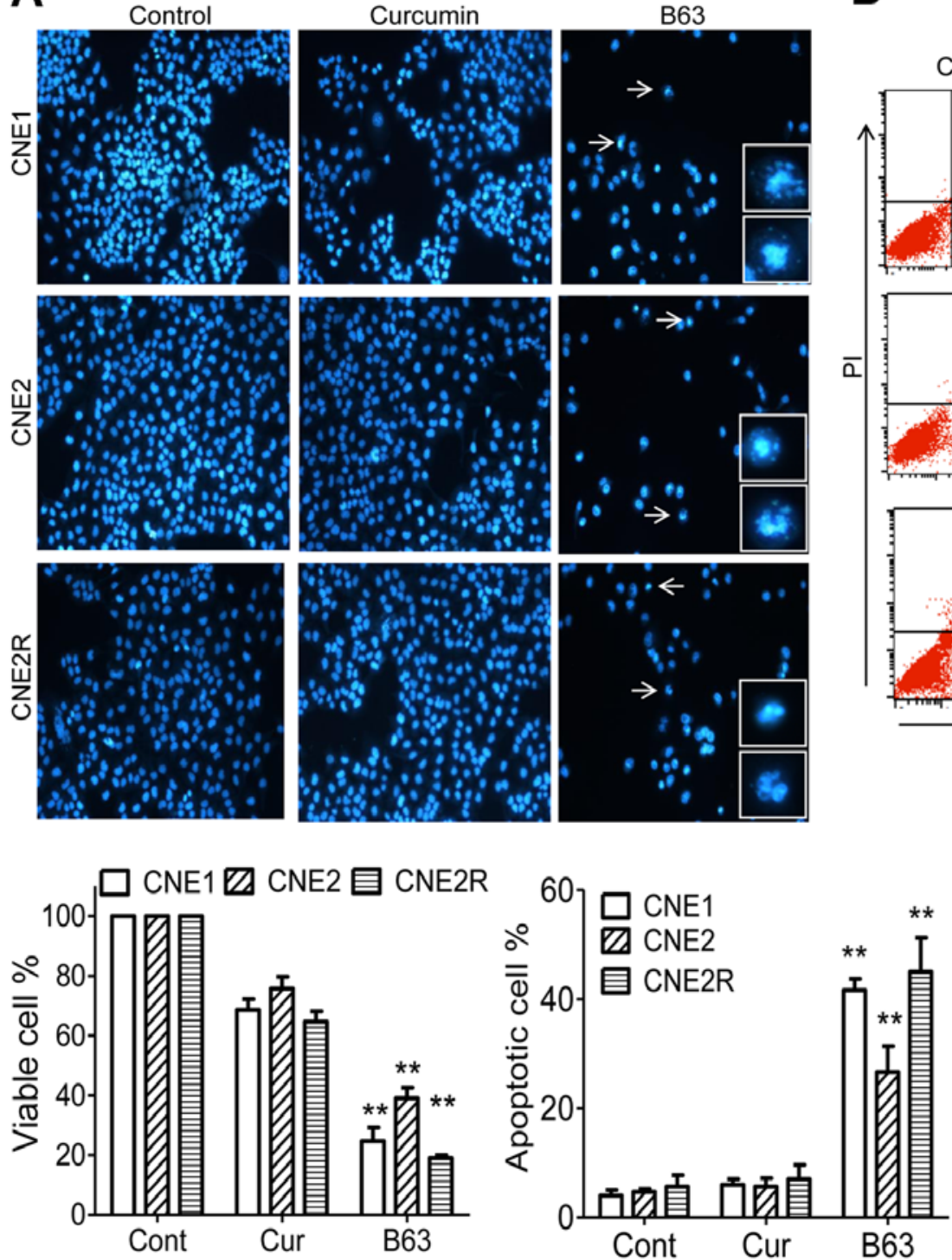

B
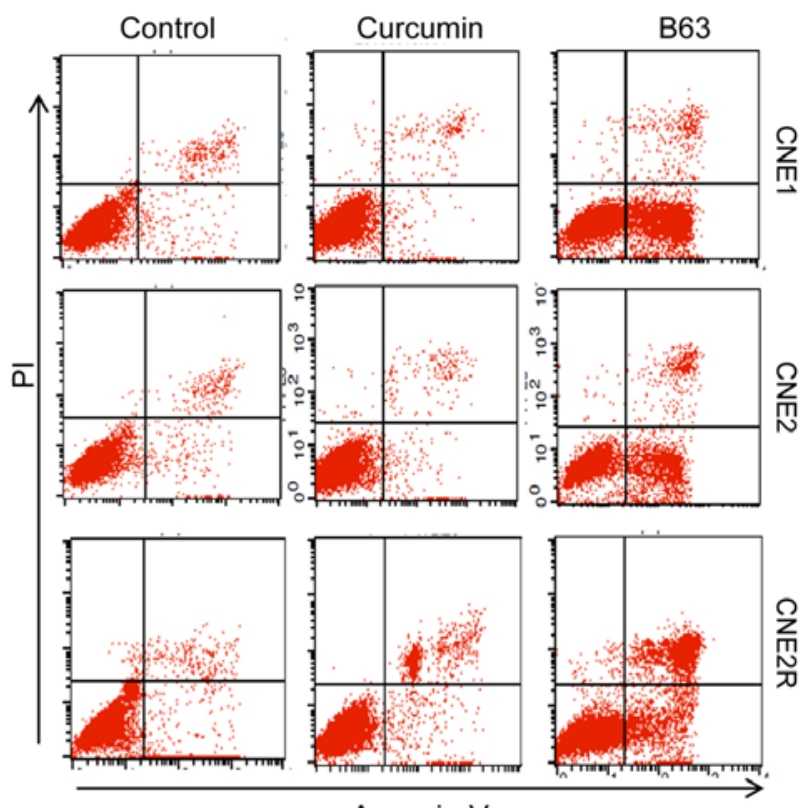

Annexin- $V$

C

Cont B63 Cur

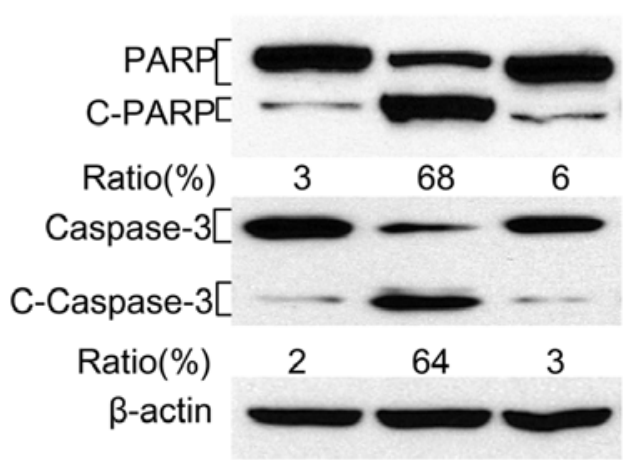

Figure 3. B63 induces apoptosis in NPC cells. Cells treated with B63 or curcumin were stained with Hoechst 33342 and then detected by fluorescence microscope, and the apoptotic cells are indicated with arrows (A) or stained with Annexin V/PI, then detected by flow cytometry (B). quantification of the viable cells and apoptotic cells. (C) Treated CNE2 cells were lysed for western blotting and then detected by cleaved PARP and Caspase-3. Cont, control; Cur, curcumin. All data represent three independent experiments, mean $\pm \mathrm{SD}$. ${ }^{* *}$ Compared with curcumin group, $\mathrm{P}<0.01$.

test the effect of B63 on NPC cell proliferation was further performed. As expected, treatment of curcumin or B63 led to decrease in colony formation when compared to the DMSO control group (Fig. 2A). Three micromolar $(3 \mu \mathrm{M})$ curcumin produced a decrease of nearly $24 \%$ (CNE1) and $20 \%$ (CNE2) in colony formation, respectively. While $3 \mu \mathrm{M}$ B63 treatment showed $99 \%$ in CNE1 and $97 \%$ in CNE2 reductions in colony numbers. These results showed that B63 was more potent than curcumin in preventing cell viability and propagation of NPC cells.

Cell cycle distribution of CNE1 and CNE2 was accessed following 24-h treatment with B63 $(5 \mu \mathrm{M})$ or curcumin. Therapy of B63 led to an increase in the G2/M phase, from 4 to $26 \%$ in CNE1 and from 4 to $24 \%$ in CNE2. Furthermore, B63 arrested NPC cells in G2/M phase in a time-dependent manner, after 36-h therapy, B63 arrested more cells in G2/M phase (47\% in CNE1 and $41 \%$ in CNE2), whereas, curcumin at the same concentration did not induce significant change in the cell cycle (Fig. 2B). By $36 \mathrm{~h}$, decrease in cyclin B expression was also observed in $\mathrm{B} 63$-treated cells relative to controls (Fig. 2C). As our previous studies demonstrated Jab1/ P27 pathway plays an important role in the pathogenesis of NPC (16), we also evaluated the effect of B63 on this pathway and found that B63 inhibited Jab1 and consequently increased P27 (Fig. 2C).

B63 promotes apoptosis in NPC cells. Next, it was determined if the B63-induced cell viability suppression was followed by increases in apoptosis. The effect of B63 on the induction of apoptosis using Hoechst fluorescence and flow cytometry was analyzed. B63 induced morphological apoptotic characteristic in NPC cells (Fig. 3A). Control cells and curcumin treated cells showed excellent growth status. Treatment with B63 resulted in a remarkable decrease in the number of viable CNE1 cells 


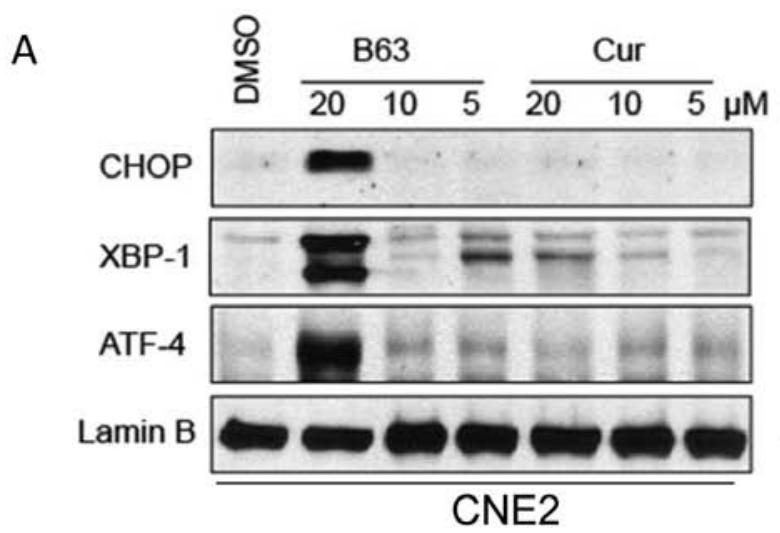

C

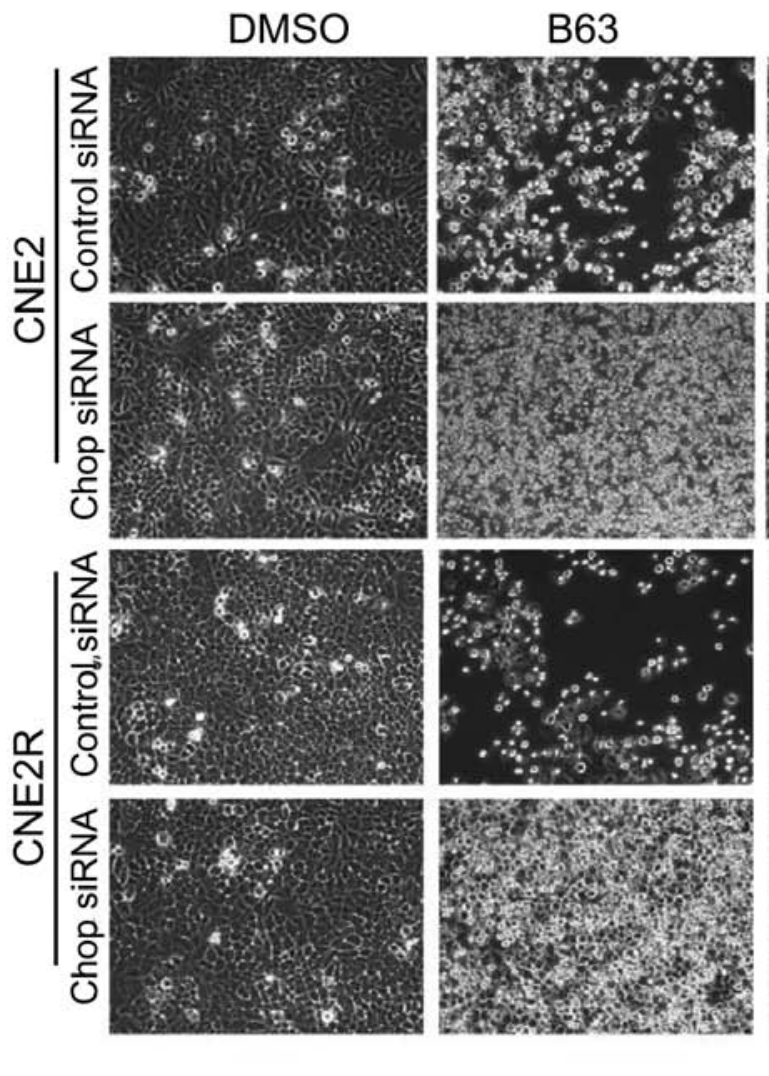

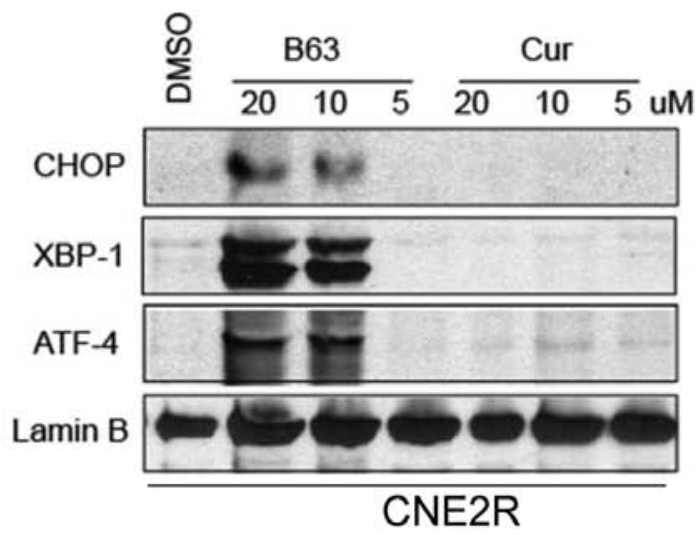

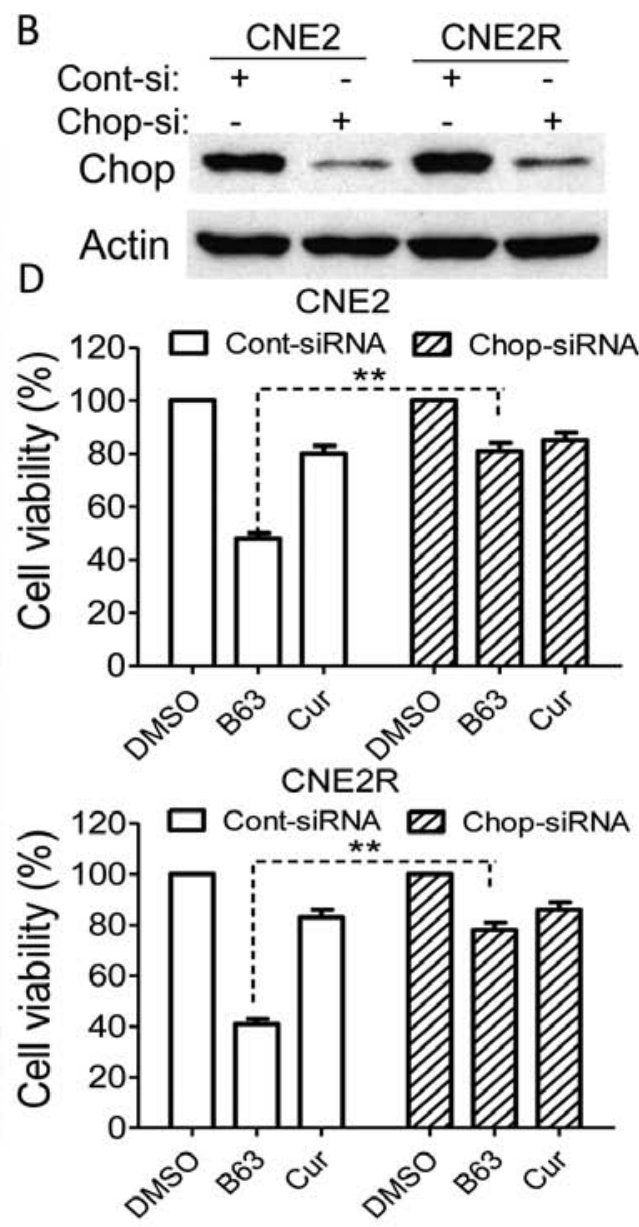

Figure 4. Depletion of CHOP attenuates the B63 antitumor activity. (A) NPC cells were treated with B63 $(5,10$ and $20 \mu \mathrm{M})$ or curcumin $(5,10$ and $20 \mu \mathrm{M})$ for $24 \mathrm{~h}$, proteins were measured by western blotting. (B and C) NPC cells were infected with CHOP siRNA virus and then treated with B63 or curcumin for $48 \mathrm{~h}$. (B) Knockdown of CHOP was confirmed by western blotting. (C) The figures were obtained using a microscope with x20 amplification. (D) The cell viability was detected using MTT assay. Cur, curcumin. All data represent three independent experiments, mean $\pm \mathrm{SD} .{ }^{* *} \mathrm{P}<0.01$.

(76\%), CNE2 cells (61\%) and CNE2R cells (81\%) compared with control cells (Fig. 3A).

Flow cytometric analysis confirmed the above morphological observations. There was no significant difference in apoptosis induction between curcumin treated group and control group. However, after the same concentration of B63 treatment, the ratios of apoptosis were $42 \%$ (CNE1), 27\% (CNE2) and 45\% (CNE2R), respectively Fig. 3B. Because cleavage of PARP and caspase-3 activation are indication of the beginning of apoptosis $(19,20)$, the influence of B63 on CNE2 cells was further examined. As expected, B63 induced more significant PARP and caspase- 3 cleavage than curcumin (Fig. 3C). These data suggested an enhanced activity of B63 in inducing apoptosis in NPC cells.

B63 specifically activated the ER stress pathway. CHOP, ATF-4 and XBP-1 are markers of ER stress (21) and prolonged activation of CHOP can trigger apoptosis in cells (22). In this study, B63 significantly elevated the CHOP, XBP-1, ATF-4 protein levels, whereas curcumin did not induce any change in these markers (Fig. 4A). The data demonstrated that B63-induced ER stress may represent a major mechanism of 
A Control Cur-10 $\mu \mathrm{M}$ B63-5 $\mu \mathrm{M}$ B63-10 $\mu \mathrm{M}$
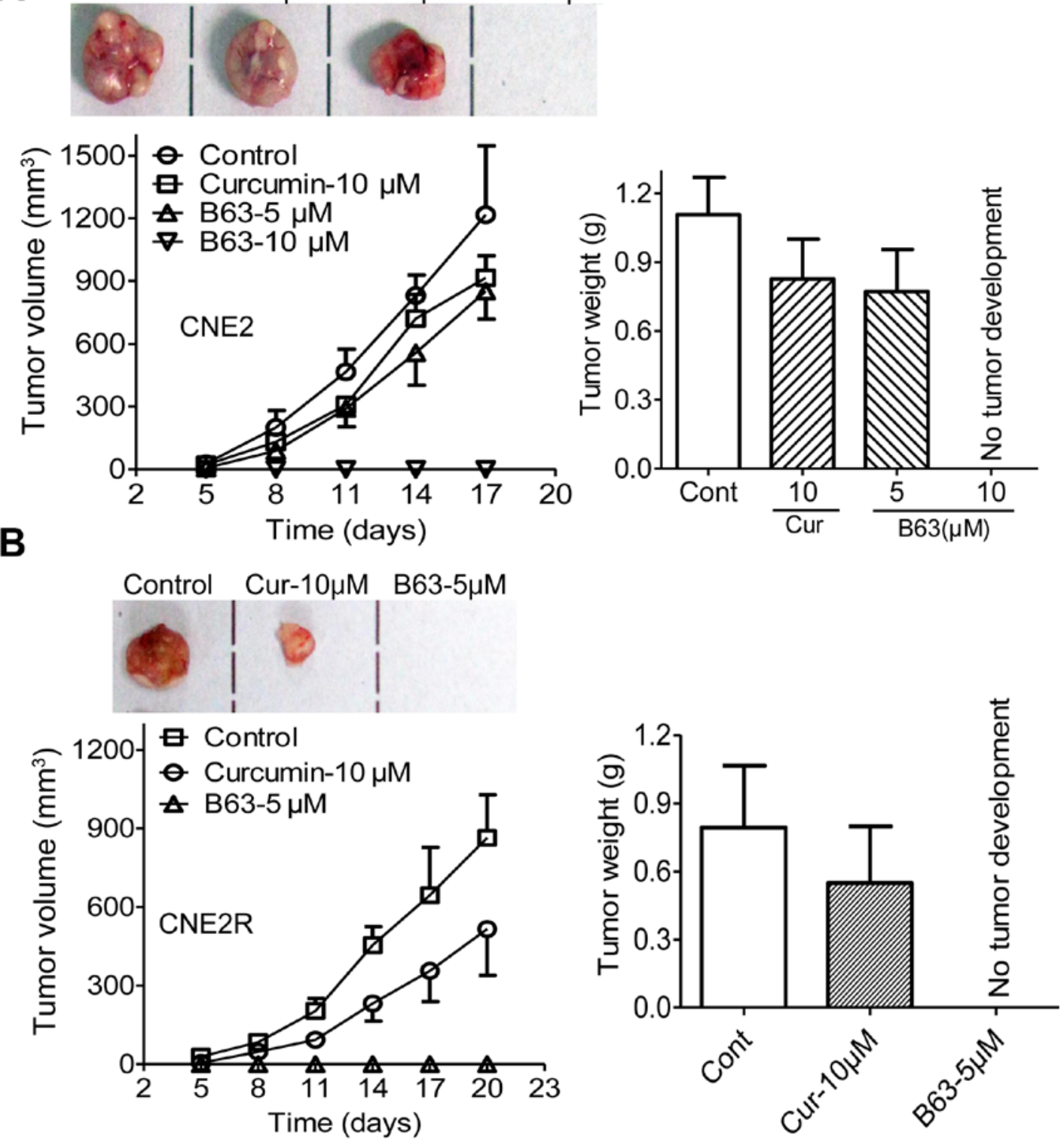

Figure 5. B63 inhibits tumorigenesis. CNE2 (A) and CNE2R (B) were treated with B63 (5 or $10 \mu \mathrm{M})$ or curcumin $(10 \mu \mathrm{M})$ for 12 h. Cells were subcutaneously injected into the flank region of female nude mice. The tumor volume was measured on the indicated days. Tumor weight was obtained at the end of the experiment.

anticancer function. For further confirmation that ER stress plays a major role in B63-induced apoptosis, lentiviral siRNA targetting CHOP gene was produced and used to infect NPC cells. The reduction of $\mathrm{CHOP}$ expression was proven using western blot assay (Fig. 4B). In addition, to prove that $\mathrm{CHOP}$ levels affected B63 activity in NPC cells, CHOP siRNA-transfected NPC cells were treated with curcumin and B63 and it was found that cell apoptosis induced by B63 in the CHOP deficient cells was significantly reduced when compared to the control cells (Fig. 4C). Besides, depletion of CHOP attenuates the cell viability inhibition induced by B63 as measured by MTT assay (Fig. 4D). These results pointed out that B63induced cell apoptosis is, at least partly, mediated via the ER stress pathway.

B63 represses tumorigenicity of NPC cells. Tumorigenicity assay in nude mice was performed to validate the B63 anti- tumor activity, CNE2 and CNE2R cells were treated with B63 (5 or $10 \mu \mathrm{M})$, curcumin $(10 \mu \mathrm{M})$ or vehicle (DMSO) for $12 \mathrm{~h}$ and were then injected subcutaneously into the flank of nude mice, and tumor formation was monitored. B63 effectively suppressed the tumor growth in mice bearing CNE2 and CNE2R cells (Fig. 5), reducing the tumor weight by $30 \%$ compared with the CNE2 control group. Furthermore, we did not observe tumor development in mice bearing CNE2 cells with $10 \mu \mathrm{M}$ B63 pretreatment or CNE2R cells with $5 \mu \mathrm{M}$ $\mathrm{B} 63$ pretreatment, supporting that $\mathrm{B} 63$ is more powerful than curcumin in preventing NPC tumorigenicity.

\section{Discussion}

Curcumin, commonly called turmeric, is a natural polyphenol derived from the Curcuma longa, and is capable of inhibiting and treating different cancers $(23,24)$. Nevertheless, the anti- 
tumor activity of curcumin is severely affected by its rapid metabolism $(10,25,26)$. Studies have reported the structural modification of curcumin and the anticancer activity of its analogs (27). Curcumin is unstable at $\mathrm{pH}>6.5$ because of its highly reactive $\beta$-diketone moiety (28). A series of monocarbonyl analogs of curcumin have been designed by removing the highly reactive $\beta$-diketone moiety in the structure of curcumin. One such compound is B63 which displayed a higher chemical stability in culture medium (15). B63 exerted antitumor activity on lung cancer cells by the induction of apoptosis, which involves the ER stress signaling pathway (15). In this study, it was demonstrated that B63 is more powerful than curcumin in preventing cell viability and propagation and further inducing G2/M arrest and apoptosis in NPC cells. The data obtained in this study also demonstrated that B63-induced apoptosis promoted PARP and caspase- 3 activation. Although curcumininduced apoptosis through the activation of caspase- 3 has been previously reported (29), we did not see cleavage of PARP and caspase- 3 changes in the curcumin treated NPC cells, which may due to the low concentration $(5 \mu \mathrm{M})$.

ER regulates the protein synthesis, folding and trafficking. When signals disturb the ER function and cause ER stress, the ER stress response is a balance between prosurvival and proapoptotic signaling pathways (21). Cells undergo apoptosis when the prosurvival responses fail $(21,30)$, which is consistant with our study that B63-induced apoptosis in NPC cells. It was found that B63 could increase XBP1, ATF-4 and CHOP, triggering ER stress-specific cascade. The upregulations of CHOP, XBP-1 and ATF-1 in the nuclei of NPC cells after B63 therapy (Fig. 4A) suggest that the B63-induced ER stress was developed into the commitment phase toward apoptosis. Cleavage and activation of procaspase- 3 have been noted in different studies on ER stress-induced human cancer cell apoptosis $(22,31,32)$. Our data also showed that B63 induced caspase-3 cleavage. Collectively, our data demonstrated that ER stress markers were induced by B63, suggesting that B63-induced apoptosis is associated with ER stress.

CHOP is considered to be a marker of commitment of ER stress-induced apoptosis (33). Knockdown of CHOP decreased ER stress-mediated apoptosis in human cancer cell (34-36). In agreement with these reports, our data also showed that depletion of CHOP attenuated the B63 antitumor activity. Besides the cellular effects, B63 prevented tumor growth in the nude mouse model.

However, other apoptotic pathways may also participate in the B63-induced apoptosis. For example, mitochondriamediated apoptotic pathway where caspase-3 activation plays an important role (37). Additionally, curcumin has been reported to exert anticancer activity through multi-targeting mechanisms $(12,23,38)$. Further studies are necessary to detect the in vivo pharmacodynamics of B63 as a candidate for inhibiting and treating different cancers.

Since many tumor cells are deficient in G1/S cell cycle checkpoint, they are more dependent on G2/M checkpoints to allow time for DNA repair. Previous studies demonstrated that tumor cells in the $\mathrm{G} 2 / \mathrm{M}$ phase are more sensitive to radiotherapy $(39,40)$. In this study, the number of NPC cells in the G2/M phase increased significantly after exposure to B63. Thus, the link between B63-induced G2/M arrest and hyper-radiosensitivity needs to be investigated in the future.
A more detailed understanding of the mechanisms of B63 induced-G2/M checkpoint activation is thus essential for the development of radiotherapy sensitizer.

In conclusion, our data indicated that B63 displayed enhanced anticancer effects on NPC through an ER stressmediated pathway, suggested B63 could become part of an effective therapeutic regimen for NPC.

\section{Acknowledgements}

This study was supported by funds from the National Natural Science Foundation of China (81270597) and the Fundamental Research Funds for the Central Universities (JUSRP115A31).

\section{References}

1. Lo KW, Chung GT and To KF: Deciphering the molecular genetic basis of NPC through molecular, cytogenetic, and epigenetic approaches. Semin Cancer Biol 22: 79-86, 2012.

2. Hui EP, Ma BB, Leung SF, King AD, Mo F, Kam MK, Yu BK, Chiu SK, Kwan WH, Ho R, et al: Randomized phase II trial of concurrent cisplatin-radiotherapy with or without neoadjuvant docetaxel and cisplatin in advanced nasopharyngeal carcinoma. J Clin Oncol 27: 242-249, 2009.

3. Chan AT: Nasopharyngeal carcinoma. Ann Oncol 21 (Suppl 7): vii308- vii 312, 2010.

4. Yip KW, Mocanu JD, Au PY, Sleep GT, Huang D, Busson P, Yeh W-C, Gilbert R, O'Sullivan B, Gullane P, et al: Combination bcl-2 antisense and radiation therapy for nasopharyngeal cancer. Clin Cancer Res 11: 8131-8144, 2005.

5. Lev-Ari S, Lichtenberg D and Arber N: Compositions for treatment of cancer and inflammation. Recent Patents Anticancer Drug Discov 3: 55-62, 2008.

6. Gandhy SU, Kim K, Larsen L, Rosengren RJ and Safe S: Curcumin and synthetic analogs induce reactive oxygen species and decreases specificity protein $(\mathrm{Sp})$ transcription factors by targeting microRNAs. BMC Cancer 12: 564, 2012.

7. Pan Y, Xiao J, Liang G, Wang M, Wang D, Wang S and Yang H: A new curcumin analogue exhibits enhanced antitumor activity in nasopharyngeal carcinoma. Oncol Rep 30: 239-245, 2013.

8. Lin SS, Huang HP, Yang JS, Wu JY, Hsia TC, Lin CC, Lin CW, Kuo CL, Gibson Wood W and Chung JG: DNA damage and endoplasmic reticulum stress mediated curcumin-induced cell cycle arrest and apoptosis in human lung carcinoma A-549 cells through the activation caspases cascade- and mitochondrialdependent pathway. Cancer Lett 272: 77-90, 2008.

9. Bakhshi J, Weinstein L, Poksay KS, Nishinaga B, Bredesen DE and Rao RV: Coupling endoplasmic reticulum stress to the cell death program in mouse melanoma cells: effect of curcumin. Apoptosis 13: 904-914, 2008.

10. Anand P, Kunnumakkara AB, Newman RA and Aggarwal BB: Bioavailability of curcumin: Problems and promises. Mol Pharm 4: $807-818,2007$.

11. Yogosawa S, Yamada Y, Yasuda S, Sun Q, Takizawa K and Sakai T: Dehydrozingerone, a structural analogue of curcumin, induces cell-cycle arrest at the G2/M phase and accumulates intracellular ROS in HT-29 human colon cancer cells. J Nat Prod 75: 2088-2093, 2012.

12. Subramaniam D, May R, Sureban SM, Lee KB, George R, Kuppusamy P, Ramanujam RP, Hideg K, Dieckgraefe BK, Houchen CW, et al: Diphenyl difluoroketone: A curcumin derivative with potent in vivo anticancer activity. Cancer Res 68: 1962-1969, 2008.

13. Liang G, Yang S, Zhou H, Shao L, Huang K, Xiao J, Huang Z and Li X: Synthesis, crystal structure and anti-inflammatory properties of curcumin analogues. Eur J Med Chem 44: 915-919, 2009.

14. Liang G, Shao L, Wang Y, Zhao C, Chu Y, Xiao J, Zhao Y, Li X and Yang S: Exploration and synthesis of curcumin analogues with improved structural stability both in vitro and in vivo as cytotoxic agents. Bioorg Med Chem 17: 2623-2631, 2009.

15. Xiao J, Wang Y, Peng J, Guo L, Hu J, Cao M, Zhang X, Zhang H, Wang Z, Li X, et al: A synthetic compound, 1,5-bis(2methoxyphenyl)penta-1,4-dien-3-one (B63), induces apoptosis and activates endoplasmic reticulum stress in non-small cell lung cancer cells. Int J Cancer 131: 1455-1465, 2012. 
16. Pan Y, Zhang Q, Tian L, Wang X, Fan X, Zhang H, Claret FX and Yang H: Jab1/CSN5 negatively regulates p27 and plays a role in the pathogenesis of nasopharyngeal carcinoma. Cancer Res 72: 1890-1900, 2012.

17. Pan Y, Wang M, Bu X, Zuo Y, Wang S, Wang D, Liu Q, Su B, $\mathrm{Xu} \mathrm{T}$, Wang $\mathrm{C}$, et al: Curcumin analogue T83 exhibits potent antitumor activity and induces radiosensitivity through inactivation of Jab1 in nasopharyngeal carcinoma. BMC Cancer 13: 323, 2013.

18. Pan Y, Zhang Q, Atsaves V, Yang H and Claret FX: Suppression of Jab1/CSN5 induces radio- and chemo-sensitivity in nasopharyngeal carcinoma through changes to the DNA damage and repair pathways. Oncogene 32: 2756-2766, 2013.

19. Lazebnik YA, Kaufmann SH, Desnoyers S, Poirier GG and Earnshaw WC: Cleavage of poly(ADP-ribose) polymerase by a proteinase with properties like ICE. Nature 371: 346-347, 1994.

20. Nicholson DW, Ali A, Thornberry NA, Vaillancourt JP, Ding CK, Gallant M, Gareau Y, Griffin PR, Labelle M, Lazebnik YA, et al: Identification and inhibition of the ICE/CED-3 protease necessary for mammalian apoptosis. Nature 376: 37-43, 1995.

21. Tabas I and Ron D: Integrating the mechanisms of apoptosis induced by endoplasmic reticulum stress. Nat Cell Biol 13: 184-190, 2011

22. Szegezdi E, Logue SE, Gorman AM and Samali A: Mediators of endoplasmic reticulum stress-induced apoptosis. EMBO Rep 7: 880-885, 2006.

23. Hatcher H, Planalp R, Cho J, Torti FM and Torti SV: Curcumin: From ancient medicine to current clinical trials. Cell Mol Life Sci 65: 1631-1652, 2008.

24. Strimpakos AS and Sharma RA: Curcumin: preventive and therapeutic properties in laboratory studies and clinical trials. Antioxid Redox Signal 10: 511-545, 2008.

25. Sharma RA, Euden SA, Platton SL, Cooke DN, Shafayat A, Hewitt HR, Marczylo TH, Morgan B, Hemingway D, Plummer SM, et al: Phase I clinical trial of oral curcumin: biomarkers of systemic activity and compliance. Clin Cancer Res 10: 6847-6854, 2004.

26. Dhillon N, Aggarwal BB, Newman RA, Wolff RA Kunnumakkara AB, Abbruzzese JL, Ng CS, Badmaev V and Kurzrock R: Phase II trial of curcumin in patients with advanced pancreatic cancer. Clin Cancer Res 14: 4491-4499, 2008.

27. Padhye S, Chavan D, Pandey S, Deshpande J, Swamy KV and Sarkar FH: Perspectives on chemopreventive and therapeutic potential of curcumin analogs in medicinal chemistry. Mini Rev Med Chem 10: 372-387, 2010.
28. Tomren MA, Másson M, Loftsson T and Tønnesen HH: Studies on curcumin and curcuminoids XXXI. Symmetric and asymmetric curcuminoids: Stability, activity and complexation with cyclodextrin. Int J Pharm 338: 27-34, 2007.

29. Moragoda L, Jaszewski R and Majumdar AP: Curcumin induced modulation of cell cycle and apoptosis in gastric and colon cancer cells. Anticancer Res 21A: 873-878, 2001.

30. Dolai S, Pal S, Yadav RK and Adak S: Endoplasmic reticulum stress-induced apoptosis in Leishmania through $\mathrm{Ca}^{2+}$-dependent and caspase-independent mechanism. J Biol Chem 286: 13638-13646, 2011.

31. Rasheva VI and Domingos PM: Cellular responses to endoplasmic reticulum stress and apoptosis. Apoptosis 14: 996-1007, 2009.

32. Schleicher SM, Moretti L, Varki V and Lu B: Progress in the unraveling of the endoplasmic reticulum stress/autophagy pathway and cancer: Implications for future therapeutic approaches. Drug Resist Updat 13: 79-86, 2010.

33. Oyadomari S and Mori M: Roles of CHOP/GADD153 in endoplasmic reticulum stress. Cell Death Differ 11: 381-389, 2004

34. Huang SM, Cheung CW, Chang CS, Tang CH, Liu JF, Lin YH, Chen JH, Ko SH, Wong KL and Lu DY: Phloroglucinol derivative MCPP induces cell apoptosis in human colon cancer. J Cell Biochem 112: 643-652, 2011

35. Ma J, Qiu Y, Yang L, Peng L, Xia Z, Hou LN, Fang C, Qi H and Chen HZ: Desipramine induces apoptosis in rat glioma cells via endoplasmic reticulum stress-dependent CHOP pathway. J Neurooncol 101: 41-48, 2011.

36. Wali VB, Bachawal SV and Sylvester PW: Endoplasmic reticulum stress mediates gamma-tocotrienol-induced apoptosis in mammary tumor cells. Apoptosis 14: 1366-1377, 2009.

37. Shelton SN, Dillard CD and Robertson JD: Activation of caspase-9, but not caspase-2 or caspase-8, is essential for heatinduced apoptosis in Jurkat cells. J Biol Chem 285: 40525-40533, 2010.

38. Freudlsperger C, Greten J and Schumacher U: Curcumin induces apoptosis in human neuroblastoma cells via inhibition of NFkappaB. Anticancer Res 28A: 209-214, 2008.

39. Krueger SA, Wilson GD, Piasentin E, Joiner MC and Marples B: The effects of G2-phase enrichment and checkpoint abrogation on low-dose hyper-radiosensitivity. Int J Radiat Oncol Biol Phys 77: $1509-1517,2010$

40. Fernet M, Mégnin-Chanet F, Hall J and Favaudon V: Control of the G2/M checkpoints after exposure to low doses of ionising radiation: Implications for hyper-radiosensitivity. DNA Repair (Amst) 9: 48-57, 2010 